\title{
THE AMS DATING OF SEPARATE FRACTIONS IN ARCHAEOLOGY
}

\author{
R J BATTEN, RICHARD GILLESPIE*, J A J GOWLETT, and \\ R E M HEDGES
}

Research Laboratory for Archaeology and the History of Art Oxford University, 6 Keble Road, Oxford OX1 3QJ, England

\section{INTRODUCTION}

The usefulness of radiocarbon dates in archaeology greatly depends on both the stratigraphic relationship of the sample submitted and on the origin and homogeneity of the measured carbon. For very small samples, stratigraphic relationships can raise additional problems of movement. In chemically well-characterized materials, the best example being collagen, the carbon source can be reasonably well purified. Many samples, however, survive as a complex mixture of high molecular weight polyphenolic materials, with properties between charcoals, humic acids, and lignins. Charred bone, eg, which rarely contains useful quantities of amino acids, and charred seeds, as well as 'charcoal,' frequently come into this category. For such samples, the likelihood of contamination by percolating soil humics is high. It is often possible to extract chemically different fractions and to compare the dates obtained. A less exact comparison can also be made for different samples from the same context. The results suggest that 'humic' acid dates can be reliable in a surprisingly frequent number of situations, and that where direct comparison is possible, the reliability can be individually assessed.

\section{CHEMISTRY OF CHARRED BONE, SEEDS, AND CHARCOAL}

The carbon content of charred bone is typically 2-10\% (ranging from $0.5-15 \%)$. Following an acid wash to remove carbonates, charred samples release a variable amount of carbonaceous material in alkaline solution, $i e$, so-called humic acid. The amount extracted increases with $\mathrm{pH}$, temperature, and time, over several hours, and may amount to the complete carbon content in some cases. We have attempted to characterize the spectrum of extractability for individual samples (see Fig 1), but samples are too variable for this to be a generally useful approach. Consequently, we have devised a flowchart (Fig 1) as a routine procedure for the pretreatment of these types of sample. This approach aims to make available more than one fraction for dating, at the same time maximizing the possibility that at least one fraction can be dated.

Figure 2 shows histograms of the yields of carbon as charcoal and as humic acid fraction from most of the samples we have treated in this way. As expected, the humic acid fraction is reasonably pure, but the charcoal residue may have a large component of extraneous material. In general, approximately equal quantities of humic and residual carbon are prepared by this method.

* Present address: Dept of Physics, University of Arizona, Tucson 


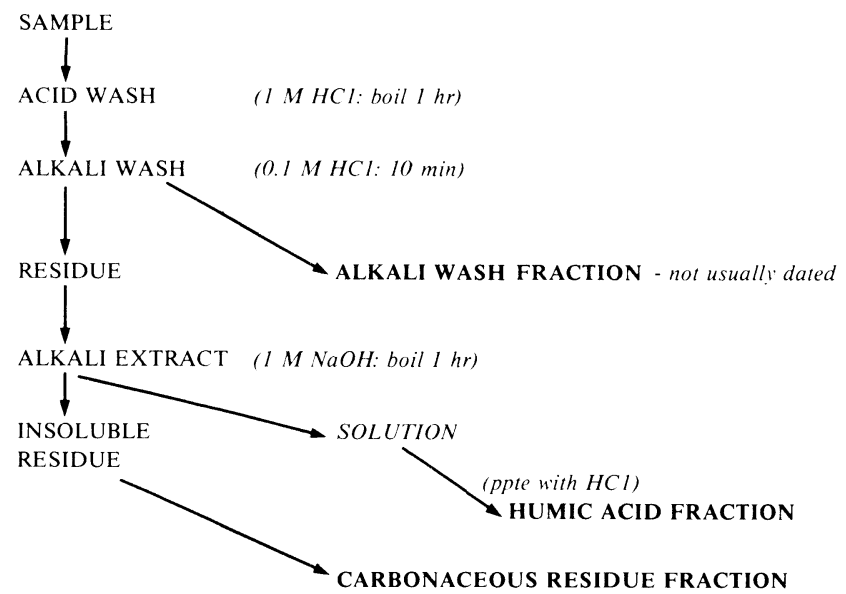

Fig 1. Flow chart for sample preparation for the dating of humic and carbonaceous materials by AMS
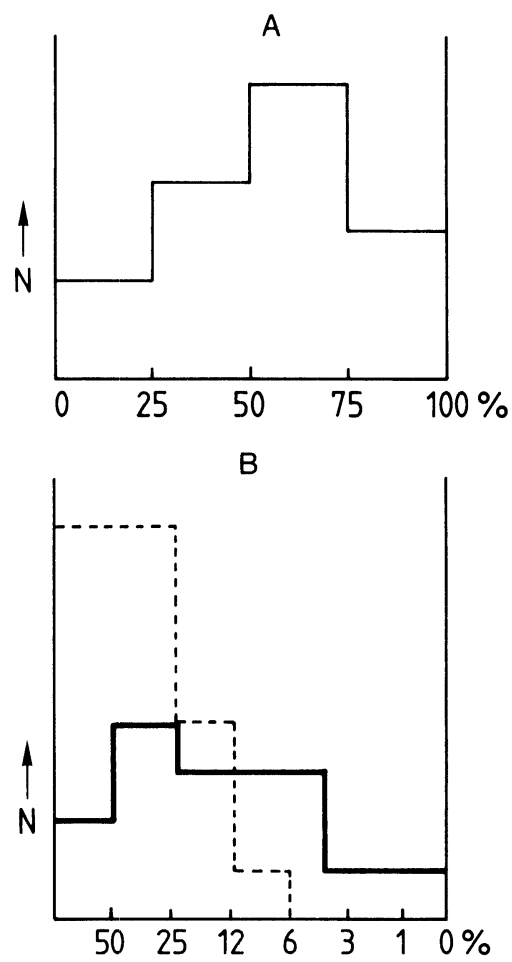

Fig 2. Histogram of yields from humic and carbonaceous materials A. The percent carbon residue as a fraction of the extracted humic carbon and residual carbon. In general, most samples yield roughly equal quantities of both fractions. (The figure does not include those samples from which only one fraction could be prepared.)

B. The distribution of carbon content in the prepared extracts. The solid line shows the distribution for the residual carbon, which may be only a small fraction of the extract; the dashed line shows the humic carbon which is usually purified to a fairly high carbon content. 


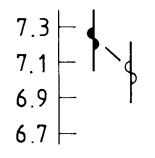

STARCEVO

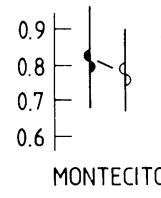

CONSISTENT

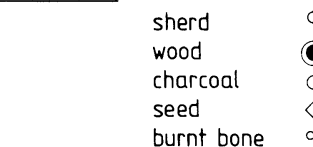

[Dates in Kyr BP]
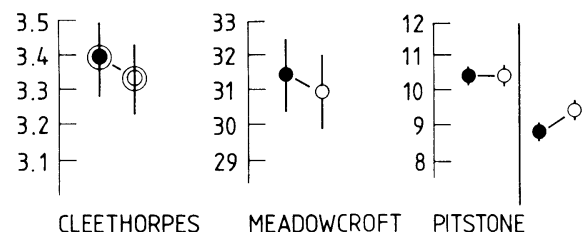

CLEETHORPES

MEADOWCROF

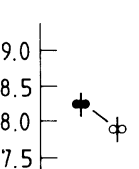

27

PAVILAND

HENGISTBURY

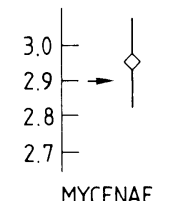

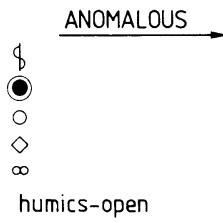

residue - solid

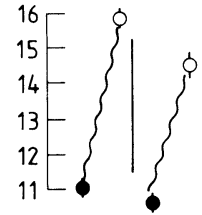

VOIDOMATIS, EPIRUS

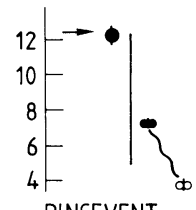

PINCEVENT

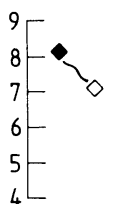

WEELDE

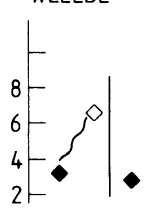

NAHAL OREN

WADI HAMMEH ABU HUREYRA - in stratigraphic order

Fig 3. A plot of the dates obtained for carbonaceous samples from a variety of sites. The vertical axis is in kilo-years. In most cases a date from a 'humic' extract can be paired with one from a 'residual carbon' extract. The differences between the consistent examples and the anomalous examples are discussed in the text.

\section{RESULTS AND DISCUSSION}

Radiocarbon dates obtained from the fractions are shown in Figure 3. In most cases a humic residual carbon pair could be compared. In some cases where only one fraction was available, comparison between separate samples from the same stratigraphic context was possible. Of the 21 or so pairs, from 14 sites, the great majority show a satisfactory consistency between the humic and charcoal pair. This applies equally to burned bone and to seeds, etc. In all these cases the date obtained is consistent with archaeologic expectations.

A fairly extensive study was made of seeds and burned bone from the site Tell Abu Hureyra (Moore, 1973). The seeds and bone give dates in good agreement with each other, and the humic/residual carbon pairs are reasonably consistent. The general trend of dates follows the stratigraphic order (there is no independent time scale), and the youngest bone humic date may be too young, but is not inconsistent with the stratigraphy.

Of the sites where consistency was not obtained, stratigraphic explanations are available for Epirus and Nahal Oren. In the first case, a hearth preserved in fine-grained river sediments, the deposit overlying the char- 
coal derives from reworked terrigenous material of a date consistent with the date obtained from the humic fraction. That a consistent process is taking place is demonstrated by a second charcoal sample giving the same results. The Nahal Oren samples come from the talus deposits outside a cave (Noy, Legge \& Higgs, 1973), and show a variability in age characteristic of a deposit containing intruded material. Again, it would appear that the humic acid age relates more closely to the context of the sample. For Weelde (Huyge \& Vermeersch, 1982; Gillespie, Gowlett \& Hedges, 1984), an acid-soluble fraction showed a much younger age than the humic age, suggesting very marked contamination by highly mobile young carbon. For the sample from Pincevent (Leroi-Gourhan \& Brézillon, 1972), no satisfactory explanation exists, although the carbon residue date is so much younger than many other dates from the same stratigraphic series (averaging ca 12,000 BP), that it very probably is intrusive. One might then expect the humic acid date to be older rather than younger, however.

\section{CONCLUSIONS}

Where only a humic acid date is available from a sample, it appears from these dates that it has a high probability of reliably dating the object, so long as the site has not been disturbed. Such disturbance can be evident if there is a strong inconsistency between the humic and residual carbon date. In general it is always best to date both fractions, for crucial samples, when this is possible. The dating of burned bone, from either the humic or residual carbon fraction, appears to give satisfactory results, and is particularly useful for sites where insufficient collagen is preserved in the unburned bone.

\section{ACKNOWLEDGMENTS}

We thank the following for their help: G N Bailey, M Julien, G Hillman, A J Legge, A M T Moore, D A Sturdy, P M Vermeersch, and D Webley.

\section{REFERENCES}

Gillespie, R, Gowlett, J A J and Hedges, R E M, 1984, Recent developments in archaeology using an accelerator: Nuclear Instruments \& Methods, v 233, no. 2, p 308-331.

Huyge, D and Vermeersch, P M, 1982, Late Mesolithic settlement at Weelde-Paardsdrank: Studia Praehist Belgica, v 1, p 117-209.

Leroi-Gourhan, A and Brézillon, M, 1972, Fouilles de Pincevent. Essai d'analyse ethnographique d'un habitat magdalénien (La section 36): Supp 7, Gallia Préhistoire.

Moore, A M T, 1975, The excavations of Tell Abu Hureyra in Syria: A preliminary report: Proc Prehist Soc, v 41, p 50-77.

Noy, T, Legge, A J and Higgs, E S, 1973, Recent excavations at Nahal Oren, Israel: Proc Prehist Soc, v 39, p 75-99. 